Dokuz Eylül Üniversitesi-Mühendislik Fakültesi

Fen ve Mühendislik Dergisi

Cilt 20, Sayı 58, Ocak, 2018
Dokuz Eylul University-Faculty of Engineering Journal of Science and Engineering Volume 20, Issue 58, January, 2018

DOI: $10.21205 /$ deufmd. 2018205810

\title{
Sol-jel Yöntemi ile Hazırlanmış ZnO Nanopartiküllerin Optimizasyonu
}

\author{
N. Funda AK AZEM*1, Işıl BİRLİK 1 \\ ${ }^{1}$ Dokuz Eylül Üniversitesi, Mühendislik Fakültesi, Metalurji ve Malzeme Mühendisliği \\ Bölümü, 35390, Buca-İzmir \\ (ORCID: 0000-0002-4446-1437; ORCID: 0000-0003-3098-2001)
}

(Alınış / Received: 20.03.2017, Kabul / Accepted: 11.12.2017, Online Yayınlanma / Published Online: 20.01.2018)

Anahtar Kelimeler Özet: Çinko oksit (ZnO) nanopartikülleri mükemmel optik, Nanopartiküller, ZnO, Sol-jel elektriksel, mekanik ve kimyasal özelliklerinden dolayı fotokatalize, kompozit malzemelere, kimyasal, gaz, buhar ve nem sensörlerine ve boyaya duyarlı güneş pillerine uygulanabilmektedir. Bu çalışmanın amacl, sol-jel yöntemiyle ZnO nanopartiküllerin sentezlenmesi ve karakterize edilmesidir. ZnO nanopartikülleri çinko asetat dihidrat ve oksalik asit dihidrat başlangıç kimyasalları ve etil alkol çözücüsü kullanılarak hazırlanmıştır. Başlangıç çözeltisi molar konsantrasyonu, pH ve kalsinasyon sıcaklığı gibi işlem parametrelerinin sentezlenen nanopartikül boyutu üzerine etkisi incelenmiştir. ZnO nanopartiküllerinin boyutu ZetaSizer cihazı kullanılarak belirlenmiştir. Sentezlenen ZnO nanopartiküllerinin yapısal ve kimyasal özellikleri X-Işını difraksiyonu (XRD) ve Fourier Dönüşümlü Kızılötesi Spektroskopisi (FTIR) ile belirlenmiştir. Elde edilen sonuçlar en düşük nanopartikül boyutunun başlangıç çözeltisinin $0,005 \mathrm{M}$ değerinde hazırlanması ve $400{ }^{\circ} \mathrm{C}$ sıcaklıkta kalsinasyon işlemine tabi tutulması sonucunda elde edildiğini göstermiștir.

\section{Optimization of ZnO Nanoparticles Prepared by Sol-Gel Technique}

\begin{tabular}{ll}
\hline Keywords & Abstract: Zinc oxide (ZnO) nanoparticles can potentially be \\
Nanoparticles, & applied to photo-catalysis, composite materials, chemical, gas, \\
ZnO, & vapor, and humidity sensors and dye-sensitized solar cells due to \\
Sol-gel & their excellent optical, electrical, mechanical and chemical \\
& properties. The aim of this study was to synthesize ZnO \\
& nanoparticles by sol-gel technique and characterize them. ZnO \\
& nanoparticles were prepared from zinc acetate dihydrate and \\
& oxalic acid dihydrate precursors and ethyl alcohol solvent. The \\
& effects of process parameters such as the precursor solution \\
& molar concentration, pH and calcination temperatures on the size \\
& of the synthesized nanoparticles were investigated. Particle size \\
& of synthesized ZnO nanoparticles was determined by using a \\
& ZetaSizer instrument. Structural and chemical properties of
\end{tabular}


synthesized $\mathrm{ZnO}$ nanoparticles were investigated by X-ray diffraction (XRD) and Fourier transform infrared spectroscopy (FTIR) respectively. Results show that the lowest $\mathrm{ZnO}$ nanoparticles size obtained with precursor solution prepared at $0.005 \mathrm{M}$ and calcined at $400{ }^{\circ} \mathrm{C}$.

*Sorumlu yazar: funda.ak@deu.edu.tr

\section{Giriş}

Nanoyapılı malzemeler boyutlarına bağlı yeni özellikler ve farklı teknolojilerde uygulama potansiyelleri sebebi ile oldukça dikkat çekmektedir. Nano malzemelerin üretiminde morfoloji ve boyutlarının ele alınması ile özelliklerinin kontrol edilmesi yönünde önemli çabalar sarf edilmektedir [1]. Nanoboyutlu ZnO yapılar güneş pilleri, gaz sensörleri, kimyasal absorbandlar, elektriksel ve optik aygitlar, sıvı faz hidrojenasyon için katalizörler ve fotokatalitik bozunma için katalizör uygulamaları için yaygın olarak çalışılmakta ve üretilmektedir [2]. Bu nedenle nanoboyutlu $\mathrm{ZnO}$ yapiların üretimi ve modifikasyonu üzerine araştırmalar oldukça dikkat çekmektedir. ZnO yapılar, önemli avantajlara sahiptir. Birincisi, sahip olduğu 3,37 eV değerindeki geniş bant aralığı ve yüksek bağlanma enerjisi (60 $\mathrm{meV}$ ) ile önemli bir yariiletkendir. İkinci olarak elektromekanik olarak eşleşmiş sensörler ve transdüser elde edilmesinde önemli bir piezoelektrik bileșendir. Son olarak, ZnO biyouyumlu oluşu sebebi ile biyomedikal uygulamalarında doğrudan kullanılabilmektedir. $\mathrm{Bu}$ benzersiz özellikleri ZnO yapıların araştırma ve uygulama çalışmalarında en önemli nanomalzemelerden biri olarak yer almasını sağlamıştır [3].

ZnO nanomalzemelerin üretimi için lazer ablasyon [4], hidrotermal yöntemler [5], elektrokimyasal çöktürme [6], sol-jel yöntemi [7], kimyasal buhar depozitleme [8] ve termal ayrışma [9] gibi birçok yöntem kullanılmaktadır. $\mathrm{Bu}$ yöntemler içerisinden sol-jel yöntemi nanopartikül hazırlanmasının kolay olması, düşük maliyetli ürünlerin büyük endüstriyel ölçekli üretime uygulanabilirliği sebebi ile oldukça yaygın olarak kullanılmaktadır [10]. Bunun yanında düşük maliyet, özel ekipman gerektirmemesi ve çözelti kompozisyonu üzerinde etkili olan farklı parametrelerin optimize edilerek özelliklerinin kontrol edilebilirliği sol-jel yönteminin önemli avantajlarıdır [11].

Sol-jel yöntemi ile üretilen malzemelerin yapısal özelliklerine etki eden birçok parametre bulunmaktadır. $\mathrm{Bu}$ parametreler sol-jel yöntemindeki hidroliz ve kondenzasyon süreçleri üzerinde önemli etkiye sahip olup en önemlileri sıcaklık, çözelti pH değeri, su/başlangıç kimyasalı oranı, çözelti konsantrasyonu, yaşlandırma ve kurutma şartlarıdır $[12,13]$.

$\mathrm{Bu}$ çalışmada, $\mathrm{ZnO}$ nanopartiküllerin sol- jel yöntemi ile üretimi gerçekleştirilmiş olup, çözelti konsantrasyonu ve nanopartikül üretimindeki kalsinasyon sıcaklığının üretilen $\mathrm{ZnO}$ nanopartiküllerin yapısal özelliklerine etkisi incelenmiştir.

\section{Materyal ve Metot}

$\mathrm{ZnO}$ nanopartiküllerin sol-jel yöntemi ile üretiminde başlangıç kimyasalı olarak çinko asetat ve oksalit asit dihidrat kullanılmıștır. Çözelti molariteleri $0,005 \mathrm{M}, 0,01 \mathrm{M}, 0,1 \mathrm{M}, 0,2 \mathrm{M}$ ve $0,3 \mathrm{M}$ olacak şekilde çinko asetat ve oksalit asit karışımları etanol kullanılarak ayrı ayrı hazırlanmış ve birbiri içerisine sürekli karıștırma koşulu altında ilave edilmiştir. Elde 
edilen viskoz çözelti ilave olarak $60 \mathrm{dk}$ boyunca karıştırılmıştır. Elde edilen çözelti $80{ }^{\circ} \mathrm{C}$ 'de 24 saat boyunca kurutulmuş ve farklı sıcaklıklarda $(400$, 500 ve $600{ }^{\circ} \mathrm{C}$ ) 2 saat süre ile kalsinasyon işlemine tabi tutularak kalsinasyon sıcaklığının nanopartikül boyutuna etkisi incelenmiştir.

Çözeltilerin $\mathrm{pH}$ değerleri WTW marka pH/Cond 3320 Set 2 model pH metre kullanılarak ölçülmüştür. Sol-jel yöntemi ile üretilen $\mathrm{ZnO}$ nanopartiküllerin faz yapıları X-Işıını difraktometre cihazı ile $40 \mathrm{kV}$ ve $36 \mathrm{~mA}$ değerlerinde $\mathrm{CuK}_{\alpha} \quad$ radyasyonu kullanılarak incelenmiștir. ZnO partiküllerin ortalama kristal boyutları Debye-Scherer eșitliği kullanılarak XRD kırınım desenlerinden elde edilmiştir.

Üretilen ZnO nanopartiküllerin ortalama boyut ölçümleri zeta metrenin dinamik ışık saçılım modu (DLS) kullanılarak ZetaSizer cihazı (Malvern Zetasizer Nano-ZS) yardımı ile ölçülmüştür. ZnO nanopartiküllerin kimyasal bağ yapısı Fourier Dönüşümlü kızlötesi Spektroskopi (FTIR, Perkin Elmer Spectrum BX) kullanılarak $650-4000 \mathrm{~cm}^{-1}$ tarama aralığında analiz edilmiştir.

\section{Bulgular}

Şekil 1'de sol-jel yöntemi ile molarite değerinin $0,1 \mathrm{M}$ olduğu başlangıç çözeltisi kullanılarak farklı kalsinasyon sicaklıklarinda $\left(400,500\right.$ ve $\left.600{ }^{\circ} \mathrm{C}\right)$ üretilen $\mathrm{ZnO}$ nanopartiküllerin X-Işını kırınım desenleri verilmiştir. Elde edilen tüm ZnO nanopartiküllerin kristal yapıda olduğu görülmektedir. Kırınım desenleri incelendiğinde elde edilen fazın tamamının hekzagonal wurtzite kristal yapısında Zincite ( $\mathrm{ZnO}$ ) fazında (JCPDS 36-1451) olduğu tespit edilmiştir. ZnO fazına ait $31,74^{\circ}, 34,40^{\circ}$, $36,24^{\circ}, \quad 47,58^{\circ}$ ve $56,64^{\circ} \quad 2 \theta$ karakteristik piklerinin sırasıly (100), (002), (101), (102) ve (110) düzlemlerine karşıllk geldiği belirlenmiştir.

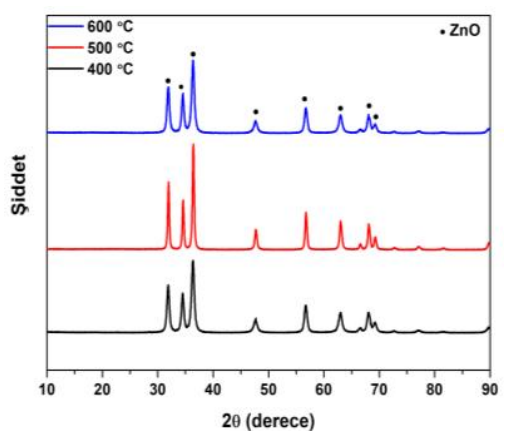

Şekil 1. 400,500 ve $600{ }^{\circ} \mathrm{C}$ kalsinasyon sıcaklıklarında üretilen $\mathrm{ZnO}$ nanopartiküllerin XRD kırınım desenleri

Üretilen ZnO nanopartiküller için kristal boyutu ölçümü Debye-Scherrer eşitliği kullanılarak hesaplanmıştır. Tablo 1'de farklı kalsinasyon sicaklıklarında üretilen $\mathrm{ZnO}$ nanopartiküllerin kristal ve partikül boyutları verilmektedir.

$$
D=\frac{0,94 \lambda}{\beta \cos \theta}
$$

Söz konusu formülde, D: kristal boyutu, $\lambda$ : $\mathrm{CuK}_{\alpha}$ radyasyonu $(1,54 \mathrm{~A}), \quad \beta$ : maksimum pikin yarı uzunluk genişliği (FWHM), $\theta$ : XRD kırınım desenindeki maksimum pikin $2 \theta$ değerinden elde edilen Bragg açısı değeridir. Çalışmada Zincite fazı için $\beta$ değeri (101) düzlemine karşılık gelen difraksiyon pikinden hesaplanmıştır. 400, 500 ve $600{ }^{\circ} \mathrm{C}$ 'de kalsinasyon işlemine tabii tutularak elde edilen $\mathrm{ZnO}$ nanopartiküllerin kristal boyutları sırasiyla $12, \quad 24$ ve $32 \mathrm{~nm}$ olarak hesaplanmıștır. Hesaplanan kristal boyutlarında artan kalsinasyon sıcaklığı ile birlikte artış görülmektedir.

Farklı sıcaklıklarda kalsinasyon işlemi uygulanmış $\mathrm{ZnO}$ nanopartiküllerin ortalama partikül boyutları 400, 500 ve $600{ }^{\circ} \mathrm{C}$ için sırasıyla 95,65, 134,7 ve 226 nm olarak ölçülmüştür. Kalsinasyon sıcaklığı ve partikül boyutu arasında 
doğrusal bir ilişki olduğu gözlemlenmektedir. Elde edilen bu sonuçla $400 \quad{ }^{\circ} \mathrm{C}^{\prime} \quad$ nin üzerindeki sıcaklıklarda partikül boyutundaki artışı tane büyümesi mekanizması ile açlklanabilir. XRD analizi ve partikül boyutu ölçümü neticesinde elde edilen sonuçlara göre üretilen $\mathrm{ZnO}$ nanopartiküllere $400{ }^{\circ} \mathrm{C}$ 'de kalsinasyon işlemi yapılması sonucu elde edilmiștir.

Tablo 1. Farklı kristalizasyon sıcaklıklarında üretilen $\mathrm{ZnO}$ nanopartiküllerin kristal ve partikül boyutu değerleri

\begin{tabular}{cccc}
\hline $\begin{array}{c}\text { Molarite } \\
\text { (M) }\end{array}$ & $\begin{array}{c}\text { Kalsinasyon } \\
\text { Sicaklığ } \\
\left({ }^{\circ} \mathbf{C}\right)\end{array}$ & $\begin{array}{c}\text { Kristal } \\
\text { Boyutu } \\
(\text { nm) }\end{array}$ & $\begin{array}{c}\text { Partikül } \\
\text { Boyutu } \\
(\mathbf{n m})\end{array}$ \\
\hline \hline 0,1 & 400 & 12 & 95,65 \\
0,1 & 500 & 24 & 134,7 \\
0,1 & 600 & 32 & 226 \\
\hline \hline
\end{tabular}

Üretilen nanopartikül boyutuna başlangıç çözeltisinin molarite değerinin etkisini incelemek amaciyla farklı molaritelerde $(0,005,0,01,0,1,0,2$ ve $0,3 \mathrm{M}$ ) çözeltiler hazırlanmış ve 400 ${ }^{\circ} \mathrm{C}$ 'de kalsinasyon işlemi uygulanmıştır. Elde edilen sonuçlar, 0,005M değerine sahip çözelti ile elde edilen ZnO nanopartiküllerin $30,11 \mathrm{~nm}$ boyutunda olduğunu göstermiştir (Tablo 2).

Tablo 2. Farklı molaritelerdeki başlangıç çözeltileri kullanılarak üretilen $\mathrm{ZnO}$ nanopartiküller için kristal boyutu ve partikül boyutu değerleri

\begin{tabular}{ccc}
\hline $\begin{array}{c}\text { Molarite } \\
\text { (M) }\end{array}$ & $\begin{array}{c}\text { Kristal } \\
\text { Boyutu } \\
\text { (nm) }\end{array}$ & $\begin{array}{c}\text { Partikül } \\
\text { Boyutu } \\
\text { (nm) }\end{array}$ \\
\hline \hline 0,005 & 16 & 30,11 \\
0,01 & 13 & 57 \\
0,1 & 12 & 95,65 \\
0,2 & 19 & 129,50 \\
0,3 & 16 & 152 \\
\hline \hline
\end{tabular}

Şekil 2'de farklı molaritelerdeki başlangıç çözeltileri kullanılarak $400^{\circ} \mathrm{C}$ kalsinasyon sıcaklığında üretilen $\mathrm{ZnO}$ nanopartiküllerin XRD kırınım desenleri verilmiștir. Tüm piklerin hekzagonal vurzit kristal yapısında zincite fazına karşılık geldiği gözlemlenmektedir. Yapıda herhangi bir yabanci faz bulunmamaktadır. XRD kırınım deseni incelendiğinde; $31,74^{\circ}, 34,40^{\circ}, 36,24^{\circ}$, $47,58^{\circ}$ ve $56,64^{\circ} \mathrm{de}$ bulunan $2 \theta$ karakteristik pikleri sirasıyla ZnO fazının (100), (002), (101), (102) ve (110) kafes düzlemlerine karşıllk gelmektedir. $\mathrm{Bu}$ değerler, JCPDS 361451 standart kart değerleriyle uyuşmaktadır. Başlangıç çözeltisinin molarite değişimi ile elde edilen fazın pik şiddetinde değişim meydana gelmediği görülmektedir.

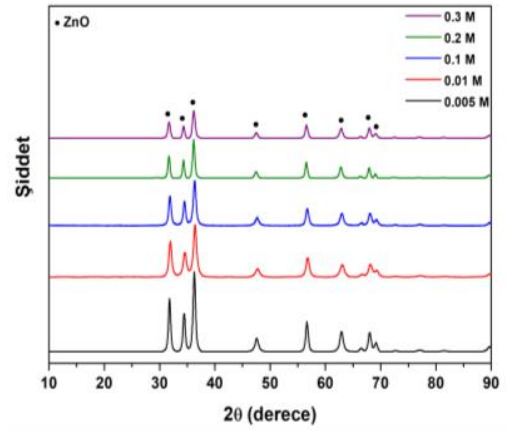

Şekil 2. Farklı molaritelerdeki başlangıç çözeltileri kullanılarak üretilen $\mathrm{ZnO}$ nanopartiküllerin XRD kırınım desenleri

Partikül boyutunun başlangıç çözeltisinin molarite ve $\mathrm{pH}$ değerine bağlı olarak değişimi Şekil 3' de verilmektedir. Elde edilen çözeltilerin pH değerleri $0,005 \mathrm{M}, 0,01 \mathrm{M}, 0,1 \mathrm{M}, 0,2 \mathrm{M}$ ve $0,3 \mathrm{M}$ molarite değerindeki çözeltiler için sırası ile 2,56, 2,23, 1,87, 1,90 ve 1,92 olarak ölçülmüştür. Elde edilen sonuçlara bakıldığında en düşük nanopartikül boyutu $30 \mathrm{~nm}$ olup 2,56 $\mathrm{pH}$ değerine sahip olan $0.005 \mathrm{M}$ başlangıç çözeltisi kullanılarak üretilmiştir. Buradan başlangıç çözeltisinin değişen molaritesi ile $\mathrm{pH}$ değerinin 1,92-2,56 aralığında değiștiği tespit edilmiştir. Literatürde çözelti $\mathrm{pH}$ değeri ile partikül boyutu ilişkisi irdelendiğinde asidik çözeltilerde artan çözelti molaritesi ile partikül boyutu arasındaki ilişkinin doğru orantılı olduğu görülmektedir [14]. Bu 
kapsamda nanopartikül üretiminin gerçekleştirildiği başlangıç çözeltisinin asidik karakterde olduğu ve molaritenin 0,3M değerine çıkması ile partikül boyutunda önemli bir artış olduğu (152 $\mathrm{nm}$ ) tespit edilmiştir. Bulunan bu sonucun Baruah ve Dutta'nın elde ettiği sonuç ile uyumlu olduğu bulunmuştur.

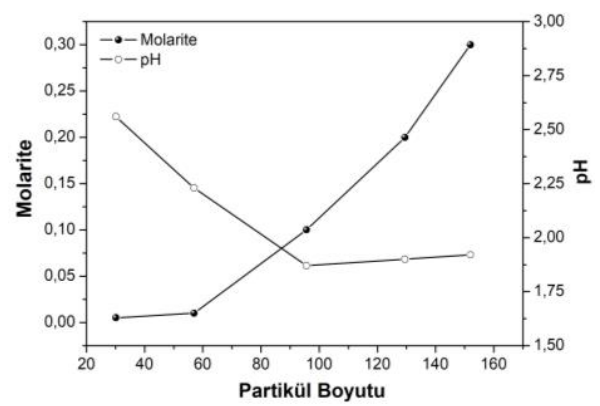

Şekil 3. Başlangıç çözeltisi molarite ve pH değerlerinin üretilen $\mathrm{ZnO}$ nanopartikül boyutuna bağlı olarak değișimi

Başlangıç çözeltisinin farklı sıcaklıklarda kalsine edilmesi ve $400{ }^{\circ} \mathrm{C}$ kalsinasyon sıcaklığında farklı molaritelerdeki başlangıç çözeltileri ile üretilen $\mathrm{ZnO}$ nanopartiküllerin FTIR spektrumları sırasıyla Şekil 4 ve Şekil 5'de verilmiştir. $708 \mathrm{~cm}^{-1}$ dalga sayısı değerinde $\mathrm{Zn}-\mathrm{O}-\mathrm{Zn}$ titreşiminden kaynaklı pik bulunmaktadır. $1063 \mathrm{~cm}^{-1}$ dalga sayısındaki pik etil alkol varlığından kaynaklanan C-O gerilme moduna karşılık gelmektedir [15]. 3200 ile $3600 \mathrm{~cm}^{-1}$ dalga sayısı aralığındaki 0$\mathrm{H}$ gerilme titreşimleri $\mathrm{ZnO}$ yapısındaki $\mathrm{H}_{2} \mathrm{O}$ varlığından kaynaklanmakta ve artan kalsinasyon sıcaklığı ile şiddeti azalmakta ve genişlemektedir. Asetat ve havada bulunan $\mathrm{CO}_{2}$ molekülleri sebebiyle $2340 \quad \mathrm{~cm}^{-1}$ dalga sayısı civarında pik oluştuğu tespit edilmiștir [16]. 2860 ve $2950 \mathrm{~cm}^{-1}$ dalga sayısı aralığında simetrik ve asimetrik $\mathrm{C}-\mathrm{H}$ bağları sebebiyle pikler ortaya çıkmıştır [17]. 1400 ve $1600 \mathrm{~cm}^{-1}$ dalga sayısı aralığında asetat grubuna ait $(-\mathrm{COOH})$ simetrik ve asimetrik gerilme modları bulunmaktadır. $\mathrm{Bu}$ grupların sentezlenme süreci sırasında nanopartikül yüzeyine absorplandığı düşünülmektedir. $1000 \mathrm{~cm}^{-1}$ dalga sayısı değerinde bulunan pik asetat grubunun C-O deformasyon moduna karşllk gelmektedir [18]. $1737 \mathrm{~cm}^{-1}$ dalga sayısı aralığında kuvvetli $\mathrm{C}=0$ bant gerilmesi görülmektedir [19]. Metal oksitler atomlar arası titreșimler sebebi ile genellikle $1000 \mathrm{~cm}^{-1}$ dalga sayısının altında absorpsiyon bandı vermektedir. Literatürde, $453 \mathrm{~cm}^{-1}$ dalga sayısı değerindeki absorpsiyon piki $\mathrm{ZnO}$ kafesindeki Zn-0 gerilme bandına karşılık gelip ZnO yapısını temsil eden karakteristik pik olarak raporlanmıştır [20].

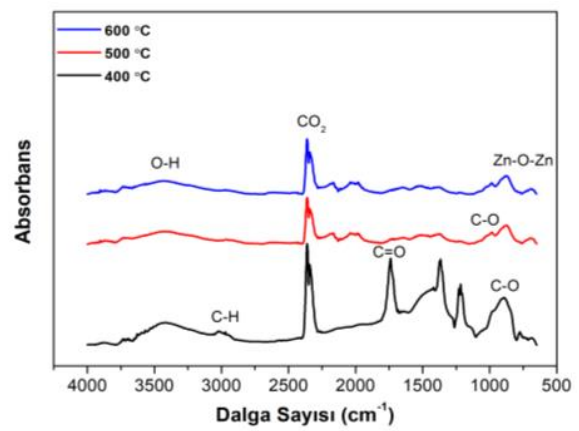

Şekil 4. 400, 500 ve $600{ }^{\circ} \mathrm{C}^{\prime}$ de kalsine edilmiş başlangıç çözeltileri ile üretilen $\mathrm{ZnO}$ nanopartiküllere ait FTIR spektrumu

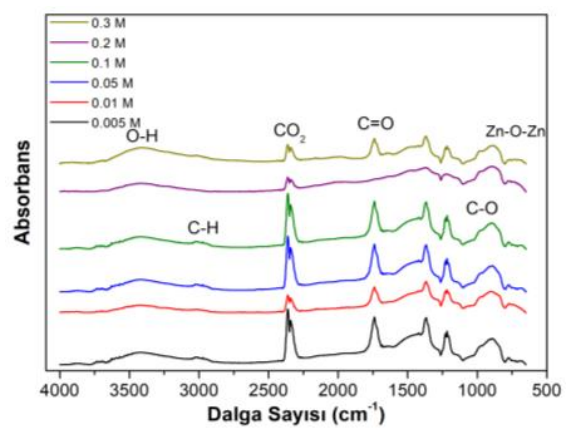

Şekil 5. Farklı molaritedeki başlangıç çözeltileri kullanılarak üretilen $\mathrm{ZnO}$ nanopartiküllere ait FTIR spektrumları 


\section{Tartışma ve Sonuç}

Çalışmada, sol-jel yöntemi ile üretilen ZnO nanopartiküllerin boyutunun başlangıç çözeltisinin molaritesi, pH değeri ve kalsinasyon sıcaklığı gibi işlem parametrelerine bağlı olarak değişimi ve bu parametrelerin üretilen nanopartiküllerin yapısal ve kimyasal özellikleri üzerine etkisi incelenmiștir. Elde edilen sonuçlar sol-jel yöntemi ile üretilen nanopartiküllerin boyutunun başlangıç çözeltisinin yüksek molarite değerlerine ve artan kalsinasyon sıcaklığına bağlı olarak arttığını göstermiş̧tir. Belirtilen koşullar altında, en düşük nanopartikül boyutu başlangıç çözeltisinin $0,005 \mathrm{M}$ değerinde hazırlanması ve $400 \quad{ }^{\circ} \mathrm{C}$ sicaklıkta kalsinasyon işlemine tabi tutulması sonucunda elde edilmiştir.

\section{Teșekkür}

$\mathrm{Bu}$ çalışma Türkiye Bilimsel ve Teknolojik Araştırma Kurumu (TUBITAK) tarafindan 113R023 numaralı proje kapsamında desteklenmiștir.

\section{Kaynakça}

[1] Sahoo, T., Kim, M., Baek, J. H., Jeon, S. R., Kim, J. S., Yu, Y. T., Lee, C. R., Lee, I. H. 2011. Synthesis and characterization of porous $\mathrm{ZnO}$ nanoparticles by hydrothermal treatment of a pure aqueous precursor, Materials Research Bulletin, Cilt. 46, s. 525-530. DOI: 10.1016/j.materresbull.2011.01.00 2

[2] Hong, R., Pan, T., Qian, J., Li, H. 2006. Synthesis and surface modification of $\mathrm{ZnO}$ nanoparticles, Chemical Engineering Journal, Cilt. 119, s. 71-81. DOI: 10.1016/j.cej.2006.03.003

[3] Wang, Z. L. 2004. Nanostructures of zinc oxide, Materials Today, s. 26-33. DOI: $10.1016 / \mathrm{S} 1369-$ 7021(04)00286-X
[4] Tan, D., Zhou S., Qiu, J., Khusro, N. 2013. Preparation of functional nanomaterials with femto second laser ablation in solution, Journal of Photochemistry and Photobiology C: Photochemistry Reviews, Cilt. 17, s. 50-68. DOI: 10.1016/j.jphotochemrev.2013.08. 002

[5] Dong, X., Yang, P., Shi, R. 2014. Fabrication of $\mathrm{ZnO}$ nanorod arrays via electrospinning assisted hydrothermal method, Materials Letters, Cilt. 135, s. 96-98. DOI: 10.1016/j.matlet.2014.07.102

[6] Chen, Y., Shen, Y., Wang, S., Huang, J. 2014. Fabrication of onedimensional $\mathrm{ZnO}$ nanotube and nanowire arrays with an anodic alumina oxide template via electrochemical deposition, Thin Solid Films, Cilt. 570, s. 303-309. DOI: 10.1016/j.tsf.2014.03.014

[7] Vafaee, M., Ghamsari, M. S. 2007. Preparation and characterization of $\mathrm{ZnO}$ nanoparticles by a novel sol-gel route, Materials Letters, Cilt. 61, s. 3265-3268. DOI: 10.1016/j.matlet.2006.11.089

[8] Wang, G. Z., Wang, Y., Yau, M.Y., To, C.Y., Deng, C.J., Dickon H.L. 2005. Synthesis of $\mathrm{ZnO}$ hexagonal columnar pins by chemical vapor deposition, Materials Letters, Cilt. 59, s. 3870-3875. DOI: 10.1016/j.matlet.2005.07.023

[9] Khalil, M. I., Al-Qunaibit, M. M., Alzahem, A. M., Labis, J. P. 2014. Synthesis and characterization of ZnO nanoparticles by thermal decomposition of a curcumin zinc complex, Arabian Journal of Chemistry, Cilt 7, s. 1178-1184. DOI: $10.1016 /$ j.arabjc.2013.10.025

[10] Anandan, S., Muthukumaran, S., Ashokkumar, M. 2014. Structural and optical properties of $\mathrm{Y}, \mathrm{Cu} \mathrm{Co}$ - 
doped $\mathrm{ZnO}$ nanoparticles by solgel method, Superlattices and Microstructures, Cilt. 74 , s. $247-$ 260. DOI: 10.1016/j.spmi.2014.07.008

[11] Reda, S. M. 2010. Synthesis of ZnO and $\mathrm{Fe}_{2} \mathrm{O}_{3}$ nanoparticles by sol-gel method and their application in dye-sensitized solar cells, Materials Science in Semiconductor Processing, Cilt. 13, s. 417-425. DOI: doi:10.1016/j.mssp.2011.09.007

[12] Yasakau, K. A., Carneiro, J., Zheludkevich, M. L., Ferreira, M. G. S. 2014. Influence of sol-gel process parameters on the protection properties of sol-gel coatings applied on AA2024, Surface \& Coatings Technology, Cilt. 246, s. 616. DOI: 10.1016/j.surfcoat.2014.02.038

[13] Milea, C.A., Bogatu, C., Duta, A. 2011. The influence of parameters in Silica sol-gel process, Bulletin of the Transilvania University of Braşov Series I: Engineering Sciences, Cilt. 4 (53).

[14] Baruah, S., Dutta, J. 2009. pHdependent growth of zinc oxide nanorods, Journal of Crystal Growth, Cilt. 311, s. 2549-2554. DOI:

10.1016/j.jcrysgro.2009.01.135

[15] Srivastava, A., Kumar, N., Misra, K. P., Khare, S. 2014. Blue-light luminescence enhancement and increased band gap from calciumdoped zinc oxide nanoparticle films, Materials Science in Semiconductor Processing, Cilt. 26, s. 259-266. DOI: 10.1016/j.mssp.2014.05.001
[16] Husainn, S., Alkhtaby, L. A., Giorgetti, E., Zoppi, A., Miranda, M. M. 2014. Effect of Mn doping on structural and optical properties of sol-gel derived $\mathrm{ZnO}$ nanoparticles, Journal of Luminescence, Cilt. 145, s. 132-137. DOI: 10.1016/j.jlumin.2013.07.003

[17] Zandi, S., Kameli, P., Salamati, H., Ahmadv, H. Hakimi, M. 2011. Microstructure and optical properties of $\mathrm{ZnO}$ nanoparticles prepared by a simple method, Physica B, Cilt. 406, s. 3215-3218. DOI: 10.1016/j.physb.2011.05.026

[18] Sharma, A., Singh, B.P., Dhar, S., Gondorf, A., Spasova, M. 2012. Effect of surface groups on the luminescence property of $\mathrm{ZnO}$ nanoparticles synthesized by solgel route, Surface Science, Cilt. 606, s. L13-L17. DOI: 10.1016/j.susc.2011.09.006

[19] Patil, S. L., Chougule, M. A., Pawar, S. G., Sen, S., Patil, V. B. 2012. Effect of Camphor Sulfonic Acid Doping on Structural, Morphological, Optical and Electrical Transport Properties on Polyaniline-ZnO Nanocomposites, Soft Nanoscience Letters, Cilt. 2, s. 46-53. DOI: 10.4236/snl.2012.23009

[20] Sohail, A., Faraz, M., Arif, H., Bhat, S. A., Siddiqui, A. A., Bano, B.2017. Deciphering the interaction of bovine heart cystatin with $\mathrm{ZnO}$ nanoparticles: Spectroscopic and thermodynamic approach, International Journal of Biological Macromolecules, Cilt. 95, s. 10561063. DOI: 10.1016/j.ijbiomac.2016.10.095 